\title{
The influence of a community-level breast-feeding promotion intervention programme on breast-feeding practices in Myanmar
}

\author{
May Me Thet ${ }^{1}{ }^{*}$, Tin Aung ${ }^{1}$, Nadia Diamond-Smith ${ }^{2}$ and May Sudhinaraset ${ }^{3}$ \\ ${ }^{1}$ Strategic Information Department, Population Services International Myanmar, No. 16 Shwe Gone Taing Street 4, \\ Yangon, Myanmar: ${ }^{2}$ Department of Epidemiology and Biostatistics, Institute for Global Health Sciences, University of \\ California-San Francisco, San Francisco, CA, USA: ${ }^{3}$ Community Health Sciences, University of California-Los \\ Angeles, Los Angeles, CA, USA
}

Submitted 16 February 2018: Final revision received 8 June 2018: Accepted 14 June 2018: First published online 15 August 2018

\begin{abstract}
Objective: Breast-feeding in the first 6 months of life is critical for ensuring both child health and well-being. Despite efforts to improve breast-feeding practices, recent studies have reported that Myanmar continues to have low rates of exclusive breast-feeding.

Design/Setting/Subjects: A community-based breast-feeding promotion programme using trained community members was implemented for 1 year in hard-to-reach townships of Myanmar. The present study assessed the breastfeeding practices using a cross-sectional survey of 610 mothers of children under 2 years old: specifically, breast-feeding within $24 \mathrm{~h}$, exclusive breast-feeding up to 6 months and breast-feeding duration.

Results: Using Cox models for breast-feeding duration before 24 months, the hazard of breast-feeding cessation was lower in programme $v$. non-programme townships (hazard ratio $(\mathrm{HR})=0.55 ; 95 \% \mathrm{CI} 0.32,0.95)$. Mothers who worked as shop owners or ran a family business had lower hazard of breast-feeding cessation ( $\mathrm{HR}=0 \cdot 13$, $P<0.05) \quad v$. those who worked as supervisors, managers, self-employed and businesswomen. The hazard of breast-feeding cessation was higher in women in higher wealth quintiles $v$. those in the lowest quintile (lower quintile, $H R=3.49$, $P<0 \cdot 1$; higher quintile, $\mathrm{HR}=3 \cdot 50, P<0 \cdot 1$; highest quintile, $\mathrm{HR}=3.47, P<0 \cdot 1$ ).

Conclusions: The intervention did not affect exclusive breast-feeding practices or breast-feeding within the first $24 \mathrm{~h}$. Potential reasons include existing high levels of early initiation of breast-feeding due to ongoing government-led maternal and child health activities, and social and traditional practices related to complementary feeding. Community-based breast-feeding programmes should continue to promote exclusive breast-feeding and develop strategies to support working mothers.
\end{abstract}

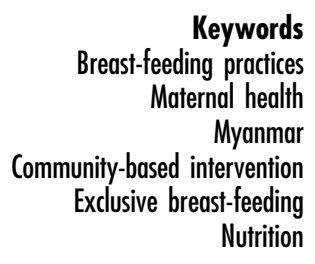

Globally, substantial evidence suggests the clear benefits of breast-feeding both for mothers and infants. A recent meta-analysis has suggested that breast milk is protective against common child infections, is beneficial to increasing intelligence and is associated with reductions in overweight and diabetes. Available evidence also suggests that early initiation of breast-feeding is associated with a reduced risk of neonatal mortality and infant morbidity ${ }^{(1,2)}$. Both neonatal mortality and morbidity can be reduced by early initiation of breast-feeding and exclusive breastfeeding during the neonatal period ${ }^{(3)}$. For mothers, breastfeeding improves birth spacing, protects against breast and ovarian cancer, and reduces type 2 diabetes ${ }^{(4)}$. Early initiation of breast-feeding within $24 \mathrm{~h}$ of birth is critical for preventing neonatal deaths ${ }^{(5)}$. Early breast-feeding initiation is also reported to be associated with better neonatal outcomes $^{(3)}$. As well, improved breast-feeding practices have been found to be associated with lower risk of developing common childhood infections such as diarrhoea and acute respiratory tract infection ${ }^{(6-8)}$.

Moreover, research also suggests that the duration of breast-feeding is important for long-term outcomes. While a longer duration of breast-feeding has been reported to have short-term benefits, it also improves outcomes across the lifespan into adulthood, including intelligence, educational achievement and income ${ }^{(9-12)}$. Breast-feeding not only provides benefits to individuals but also to larger public health concerns by protecting against overweight 
and obesity ${ }^{(13)}$. Past literature suggests that breast milk provides all the nutrients infants need in their first 6 months of life ${ }^{(14)}$. Consequently, it is recommended that women should initiate breast-feeding within the first hour after birth, exclusively breast-feed for the first 6 months and continue breast-feeding for 2 years or more.

Despite recommendations by the Government of Myanmar regarding breast-feeding practices, the recent Demographic and Health Survey revealed that only $51 \%$ of children under 6 months old were exclusively breastfed, $87 \cdot 1 \%$ were breast fed until the age of 12-17 months and $67.9 \%$ were breast-fed until 18-23 months old ${ }^{(15)}$. Past research in Myanmar suggests that despite high levels of knowledge of the benefits of breast-feeding and exclusive breast-feeding, there continue to be barriers in practice ${ }^{(16)}$. Specific barriers include beliefs that breast-feeding is not sufficient for babies' nutritional needs, labour demands and challenges, and low support from family members to exclusively breast-feed ${ }^{(16-18)}$. Barriers to mothers in Myanmar have been found to be associated with cultural beliefs and perceptions as well as knowledge on exclusive and breast-feeding practices ${ }^{(19)}$. Maternal socio-economic status was also associated with intention to exclusively breast-feed $^{(18)}$. Even though Myanmar has made significant progress towards achieving Millennium Development Goal 4, there is much to be done in improving mortality rates of infants and children under 5 years of age compared with other countries with similar resources and settings ${ }^{(20)}$. To date, there remains a dearth of studies that examine the effect of breast-feeding promotion interventions, especially in hard-to-reach areas of Myanmar.

Community-based promotion of breast-feeding practices has been shown to be effective in Myanmar and similar settings. For example, anecdotal evidence showed that a UNICEF programme aimed at deploying community health workers increased women's knowledge of the benefits of breast-feeding for children ${ }^{(21)}$. Additionally, a community-based approach aimed at behavioural change communication of maternal and newborn health was reported to be successful in a township located in the Ayeyarwaddy division of Myanmar as well as in Paki$\operatorname{stan}^{(22)}$. That programme employed a positive deviance approach using community volunteers, which identifies individuals with a good outcome (in this case, exclusive breast-feeding) despite having a high risk for a bad outcome. These positive deviants were encouraged to share their experiences with their community members to enable them to adopt the positive behaviours of both maternal and newborn health-care practices. In other countries in South and South-East Asia, community-based interventions aiming to increase knowledge and behaviours surrounding breast-feeding have been found to be successful $^{(23,24)}$.

The objective of the current study was to examine whether breast-feeding promotion at the community level increased levels of breast-feeding within $24 \mathrm{~h}$, exclusive breast-feeding up to 6 months and the duration of breastfeeding among selected women living in Myanmar. Specifically, the present paper describes these three breast-feeding practices among mothers of children under 2 years of age in hard-to-reach townships of Myanmar.

\section{Methods}

\section{Setting and programme description}

From October 2014 to September 2016, Population Services International Myanmar (PSI/M) worked in hardto-reach townships of Myanmar to improve maternal, neonatal and child health through a network of privatesector channels. The hard-to-reach townships were located in hilly and plain regions of Upper Myanmar and delta regions of Lower Myanmar that were selected for the programme based on indicators suggesting high health needs, low service coverage in reproductive, maternal and child health, and high poverty levels. As part of this larger programme, PSI/M implemented a community-based breast-feeding promotion and education intervention. $\mathrm{PSI} / \mathrm{M}$ recruited and partnered with a network of community health workers called inter-personnel communicators to work on the promotion of breast-feeding practices in programme townships. PSI/M developed the training guide and tools for these community workers. The training was led by the PSI/M field team and consisted of classroom-based lectures, discussions, role-playing and technical skills, as well as communication skills. The training used printed materials prepared by UNICEF Myanmar, such as breast-feeding flipcharts and pamphlets. Trained community health workers visited communities and led health education sessions for women of reproductive age or mothers of children under 5 years of age. Health education sessions were held at common community gathering places like schools, monasteries, religious community halls and premises of community leaders. Each interactive session lasted approximately $2 \mathrm{~h}$ and included information on nutrition, exclusive breastfeeding practices and benefits of breast-feeding. Printed materials explaining the benefits of breast-feeding and encouraging exclusive breast-feeding were also distributed during these community education sessions.

Throughout the programme period, only twenty-one townships received the PSI/M community-based breastfeeding promotion activities of inter-personnel communicators among thirty-four programme townships, because thirteen of the townships already had maternal and child health programme activities by other agencies or had no PSI/M network.

\section{Study design and recruitment}

A cross-sectional study with a multistage cluster sampling approach was conducted at the end of the programme. Ten townships were selected using probability 
proportional to size from the project townships. According to the population distribution of Myanmar and in the project townships, $20 \%$ of the sample distribution was from urban areas and $80 \%$ was from rural areas. A total of 16859 households were screened to obtain a final sample size of 2284 households with currently married women of reproductive age (18-49 years). A total of 455 (16.6\%) needed to be replaced because eligible women were not available at the time of survey. Replacement was made by visiting an adjacent household with an eligible woman.

\section{Data collection}

The survey questionnaire was modified from the 20092010 Multiple Indicators Cluster Survey (MICS) in Myanmar. The survey included eleven different modules, including demographic information on household members, water and sanitation practices, women's demographic profile and household socio-economic status, fertility history and preferences, maternal health services utilization, contraceptive use, cervical cancer prevention services received, health-seeking behaviour for diarrhoea and acute respiratory infection, exposure to PSI/M community-based activities, and feeding practices of infants and young children (see online supplementary material). To minimize potential biases, PSI/M hired an outside independent research firm in Myanmar to conduct and collect all data. The research firm was not aware of which communities received what intervention. Additionally, researchers from the University of California-Los Angeles and the University of California-San Francisco supported the analyses to further provide external validation of results. The survey tool was first translated into Myanmar and then back-translated into English. The questionnaire was also pre-tested and modified before the actual survey.

After obtaining verbal informed consent, face-to-face interviews were done with the respondents at their homes or at places of their own choice using a paper-based questionnaire. The data collection period was from August to September 2016. The interviewer went from household to household to identify eligible respondents using a screening questionnaire, which consisted of a set of screening criteria. Screening criteria included woman aged 18-49 years, currently married and being a usual resident of the project township. Women who did not give consent to participate and were not available after two visits were not included in the survey.

\section{Measures}

There were three outcomes of interest for the present study: (i) initiation of breast-feeding within $24 \mathrm{~h}$ (measured as a binary variable: yes/no); (ii) duration of breastfeeding in months (measured as a continuous variable); and (iii) exclusive breast-feeding for 6 months (measured as a binary variable: yes/no). To determine the outcomes, we used the questions 'How long after birth did you first put him/her to your breast?' for the first outcome, 'Up to which months of his/her age have you breast-fed your child?' for the second, and 'For how many months did you feed your baby nothing but breast milk?' and 'At what month did you first give your baby water?' for the third outcome. Predictors included variables related to women's demographic and socio-economic characteristics, residential area, migration status and maternal health services utilization. Age was categorized into four different age groups as 18-24 years, 25-30 years, 31-39 years and 4049 years. Age at marriage was categorized as $<18$ years, 18-24 years, 25-30 years, 31-39 years and 40-49 years. Education was split into four categories: illiterate or no formal education; primary education; secondary education; and university education. Occupational status was broken down into four groups: management and supervisory staff, self-employed and businesswomen; shop owners and family business; unskilled workers; and unemployed women and housewives. Parity was grouped into four categories: $0-1,2-3,4-5$ and $\geq 6$. Wealth quintiles were created using the principal component analysis method, which included a number of questions about house materials and access to electricity, etc. ${ }^{(25)}$. Maternal health services utilization was measured by two different variables. The first one was number of antenatal care visits, categorized as no antenatal care, one to four visits and more than four visits; the second one was the place of delivery of her recent child (home $v$. facility).

\section{Analyses}

The present paper includes only those women who had a child under 2 years of age, to assess breast-feeding practices. In total, 610 women were included in the analysis. The first descriptive analyses were conducted including $\chi^{2}$ tests for categorical variables and $t$ tests for continuous variables. Kaplan-Meier survival curves were used to assess duration of breast-feeding practices in months by women who lived in programme $v$. non-programme townships. We tested for statistical significant differences using the Wilcoxon log-rank test. Second, multivariable logistic regression was used to assess differences between programme and non-programme townships controlling for state-level differences and other factors including possible bias known to be associated with breast-feeding practices in this population. Cox proportional hazards models were conducted to assess time-to-event data (cessation of breast-feeding before 24 months). The proportional hazards assumption was assessed using Schoenfeld residuals and a global test of proportionality. The main predictor on our outcome of interest was living in an area with breast-feeding promotion activities $v$. not living in an area with breast-feeding promotion activities at endline.

All statistical analyses were conducted using the statistical software package Stata version 13.0. All study 
documents were reviewed and approved by the PSI/M Research Ethics Board for ethical clearance.

\section{Results}

\section{Demographic characteristics}

Demographic characteristics of the women who participated in the survey are described in Table 1. Age group distribution between programme and non-programme townships was similar. Age at marriage was significantly different between the programme and non-programme townships $(P<0.05)$. There were more women who got married while they were $<18$ years old in programme townships (19.2 v. 11.0\%, respectively; $P=0 \cdot 012$ ).

While education status was not different between programme and non-programme townships, occupation status was different between the two groups at $P<0 \cdot 001$. Non-programme townships had higher unemployment levels compared with programme townships: unemployed or housewives contributed the largest group in nonprogramme townships ( $82 \cdot 6 v \cdot 63 \cdot 3 \%$, respectively), while other categories were more highly represented in programme townships. Other demographic characteristics, migration status, parity and maternal health services utilization were not different between the two groups.

\section{Influence of community breast-feeding promotion activities on practices}

Table 2 presents breast-feeding practices in programme townships and non-programme townships. Breast-feeding within $24 \mathrm{~h}$ was slightly lower in programme townships (89.6\%) than non-programme townships (93.1\%) but the difference was not statistically significant $(P=0 \cdot 214)$. Exclusive breast-feeding up to 6 months was slightly higher in programme townships compared with nonprogramme townships, although this was not statistically significant ( $46 \cdot 6 v .42 .5 \%$, respectively; $P=0.453$ ). We also assessed duration of breast-feeding using Kaplan-Meier survival curves. We found that women in the programme townships had a lower probability of breast-feeding cessation compared with the non-programme townships $(P=0 \cdot 031$; Fig. 1).

\section{Multivariable regression analyses}

Multivariate logistic regression analyses were conducted to assess the statistical significance of differences in rates of breast-feeding within $24 \mathrm{~h}$ and exclusive breast-feeding up to 6 months between programme and non-programme townships. Table 3 describes the results of multivariate logistic regression models controlling for demographic characteristics, socio-economic status, migration status and maternal health services utilization. There was no difference in breast-feeding within $24 \mathrm{~h}$ between programme and non-programm townships after controlling for potential confounders. Age at marriage was found to be associated with breast-feeding within $24 \mathrm{~h}$. Women who got married between 18 and 24 years of age were more likely to breast-feed within $24 \mathrm{~h}$ than those who got married at $<18$ years old (adjusted OR $(\mathrm{AOR})=1.96$, $P<0 \cdot 1$ ). Looking at exclusive breast-feeding, no difference was seen between programme and non-programme townships after controlling for potential confounders. Urban mothers were less likely to exclusively breast-feed their baby up to 6 months $(\mathrm{AOR}=0.53, P<0.05)$ compared with rural mothers. Wealth quintile was also associated with exclusive breast-feeding up to 6 months, as women in higher wealth quintiles were more likely to exclusively breast-feed up to 6 months compared with those in the lowest quintile (lower quintile, $\mathrm{AOR}=2 \cdot 01$, $P<0.1$; higher quintile, $\mathrm{AOR}=2.77, \quad P<0.001$; highest quintile, $\mathrm{AOR}=2 \cdot 71, P<0 \cdot 05)$.

Using Cox models for time-to-event data (breast-feeding duration before 24 months), the hazard of breast-feeding cessation was lower in townships that had breast-feeding promotion activities compared with townships that did not (hazard ratio $(\mathrm{HR})=0.55 ; 95 \%$ CI $0.32,0.95)$, controlling for demographic characteristics (Table 4). Other demographic characteristics associated with breast-feeding cessation included occupation of mothers and wealth quintile. Mothers who worked as shop owners or ran family businesses had lower hazard of breast-feeding cessation than those working as management and supervisory staff, self-employed women and businesswomen $(\mathrm{HR}=0 \cdot 13, P<0 \cdot 05)$. The hazard of breast-feeding cessation was higher in women in higher wealth quintiles compared with those in the lowest quintile (lower quintile, $\mathrm{HR}=3.49, \quad P<0.1$; higher quintile, $\mathrm{HR}=3.50, \quad P<0 \cdot 1$; highest quintile, $\mathrm{HR}=3 \cdot 47, P<0 \cdot 1)$.

\section{Discussion}

Evidence from the present study suggests that a community-based breast-feeding promotion programme positively influenced breast-feeding practices in Myanmar, specifically duration of breast-feeding practice. Results suggest that the programme significantly increased duration of breast-feeding practices in townships that had the programme. No effects were found for the programme on exclusive breast-feeding practices and breast-feeding during the first $24 \mathrm{~h}$. This suggests that while the programme may have changed duration of breast-feeding, exclusive breast-feeding may be more difficult to change during the programme period of 1 year. Potential explanations for the null findings in exclusive breast-feeding and early initiation include the importance of complementary feeding as a cultural and traditional norm in Myanmar $^{(16)}$, particularly in rural areas ${ }^{(21)}$. This includes giving water, juices and rice to babies younger than 6 months ${ }^{(21)}$. Additionally, lack of knowledge, 
Table 1 Population characteristics of 18-49-year-old women with a child under 2 years of age according to receipt of a community-level breast-feeding promotion intervention on breast-feeding practices, Myanmar, August-September 2016

\begin{tabular}{|c|c|c|c|c|c|}
\hline \multirow[b]{2}{*}{ Characteristic } & \multicolumn{2}{|c|}{$\begin{array}{l}\text { Programme } \\
\text { townships }\end{array}$} & \multicolumn{2}{|c|}{$\begin{array}{l}\text { Non-programme } \\
\text { townships }\end{array}$} & \multirow[b]{2}{*}{$P$ value } \\
\hline & $n$ & Column \% & $n$ & Column \% & \\
\hline \multicolumn{6}{|l|}{ Age } \\
\hline $18-24$ years & 116 & $25 \cdot 0$ & 36 & 24.7 & \multirow[t]{5}{*}{0.957} \\
\hline $25-30$ years & 160 & 34.5 & 53 & $36 \cdot 3$ & \\
\hline $31-39$ years & 159 & $34 \cdot 3$ & 47 & $32 \cdot 2$ & \\
\hline 40-49 years & 29 & $6 \cdot 3$ & 10 & $6 \cdot 8$ & \\
\hline Total $(n 610)$ & 464 & $100 \cdot 0$ & 146 & $100 \cdot 0$ & \\
\hline \multicolumn{6}{|l|}{ Age at marriage } \\
\hline$<18$ years & 89 & $19 \cdot 2$ & 16 & $11 \cdot 0$ & \multirow[t]{5}{*}{0.012} \\
\hline $18-24$ years & 294 & 63.4 & 108 & 74.0 & \\
\hline $25-30$ years & 66 & $14 \cdot 2$ & 22 & $15 \cdot 1$ & \\
\hline $31-39$ years & 15 & $3 \cdot 2$ & 0 & 0.0 & \\
\hline Total $(n 610)$ & 464 & $100 \cdot 0$ & 146 & $100 \cdot 0$ & \\
\hline \multicolumn{6}{|l|}{ Education status } \\
\hline Illiterate or no formal education & 51 & $11 \cdot 1$ & 21 & $14 \cdot 6$ & \multirow[t]{5}{*}{0.197} \\
\hline Primary education & 159 & 34.6 & 42 & 29.2 & \\
\hline Secondary education & 211 & $45 \cdot 9$ & 74 & 51.4 & \\
\hline University education & 39 & 8.5 & 7 & 4.9 & \\
\hline Total $(n 604)$ & 460 & $100 \cdot 0$ & 144 & $100 \cdot 0$ & \\
\hline \multicolumn{6}{|l|}{ Occupation category } \\
\hline Professional: management and supervisory staff, self-employed, businesswoman & 26 & 5.7 & 4 & $2 \cdot 8$ & \multirow[t]{5}{*}{$<0.001$} \\
\hline Shop owner, family business & 27 & 5.9 & 7 & 4.9 & \\
\hline Unskilled worker & 116 & $25 \cdot 2$ & 14 & $9 \cdot 7$ & \\
\hline Unemployed/housewife & 291 & 63.3 & 119 & $82 \cdot 6$ & \\
\hline Total $(n 604)$ & 460 & $100 \cdot 0$ & 144 & $100 \cdot 0$ & \\
\hline \multicolumn{6}{|l|}{ Parity } \\
\hline $0-1$ & 167 & $36 \cdot 0$ & 41 & $28 \cdot 1$ & \multirow[t]{5}{*}{$0 \cdot 115$} \\
\hline $2-3$ & 191 & $41 \cdot 2$ & 67 & $45 \cdot 9$ & \\
\hline $4-5$ & 79 & $17 \cdot 0$ & 23 & $15 \cdot 8$ & \\
\hline$\geq 6$ & 27 & $5 \cdot 8$ & 15 & $10 \cdot 3$ & \\
\hline Total $(n 610)$ & 464 & $100 \cdot 0$ & 146 & $100 \cdot 0$ & \\
\hline \multicolumn{6}{|l|}{ Migrant } \\
\hline No & 350 & $75 \cdot 4$ & 99 & $67 \cdot 8$ & 0.068 \\
\hline Yes & 114 & $24 \cdot 6$ & 47 & $32 \cdot 2$ & \\
\hline Total $(n$ 610) & 464 & 100.0 & 146 & 100.0 & \\
\hline Residential area & & & & & \\
\hline Urban & 377 & $81 \cdot 3$ & 124 & 84.9 & 0.311 \\
\hline Rural & 87 & 18.8 & 22 & $15 \cdot 1$ & \\
\hline Total $(n 610)$ & 464 & 100.0 & 146 & 100.0 & \\
\hline State & & & & & \\
\hline Ayeyarwaddy & 193 & $41 \cdot 6$ & 51 & 34.9 & $<0.001$ \\
\hline Chin & 95 & 20.5 & 0 & 0.0 & \\
\hline Kayah & 0 & 0.0 & 95 & $65 \cdot 1$ & \\
\hline Magway & 93 & $20 \cdot 0$ & 0 & 0.0 & \\
\hline Shan & 83 & 17.9 & 0 & 0.0 & \\
\hline Total ( $n$ 610) & 464 & $100 \cdot 0$ & 146 & $100 \cdot 0$ & \\
\hline Wealth quintile & & & & & \\
\hline Lowest quintile & 59 & $12 \cdot 7$ & 19 & 13.0 & 0.218 \\
\hline Lower quintile & 78 & $16 \cdot 8$ & 37 & $25 \cdot 3$ & \\
\hline Middle quintile & 112 & 24.1 & 29 & 19.9 & \\
\hline Higher quintile & 98 & $21 \cdot 1$ & 29 & 19.9 & \\
\hline Highest quintile & 117 & $25 \cdot 2$ & 32 & 21.9 & \\
\hline Total $(n 610)$ & 464 & $100 \cdot 0$ & 146 & $100 \cdot 0$ & \\
\hline Antenatal care & & & & & \\
\hline No antenatal care & 25 & $5 \cdot 4$ & 8 & 5.6 & 0.963 \\
\hline $1-4$ visits & 107 & $23 \cdot 3$ & 35 & $24 \cdot 3$ & \\
\hline$>4$ visits & 328 & 71.3 & 101 & $70 \cdot 1$ & \\
\hline Total $(n$ 604) & 460 & $100 \cdot 0$ & 144 & $100 \cdot 0$ & \\
\hline Place of delivery & & & & & \\
\hline Home & 258 & $55 \cdot 7$ & 80 & $55 \cdot 2$ & 0.907 \\
\hline Facility & 205 & 44.3 & 65 & 44.8 & \\
\hline Total (n 608) & 463 & $100 \cdot 0$ & 145 & $100 \cdot 0$ & \\
\hline
\end{tabular}


Table 2 Breast-feeding rates among 18-49-year-old women with a child under 2 years of age according to receipt of a community-level breast-feeding promotion intervention on breast-feeding practices, Myanmar, August-September 2016

\begin{tabular}{|c|c|c|c|c|c|c|c|}
\hline & \multicolumn{2}{|c|}{ Programme townships } & \multicolumn{2}{|c|}{ Non-programme townships } & \multirow[b]{2}{*}{$P$ value } & \multicolumn{2}{|c|}{ Total } \\
\hline & $n$ & $\%$ & $n$ & $\%$ & & $n$ & $\%$ \\
\hline \multicolumn{8}{|c|}{ Breast-feeding within $24 \mathrm{~h}$} \\
\hline No $(n 58)$ & 48 & $10 \cdot 4$ & 10 & 6.9 & 0.214 & 58 & 9.5 \\
\hline Yes $(n 550)$ & 415 & 89.6 & 135 & 93.1 & & 550 & 90.5 \\
\hline Total ( $n$ 608) & 463 & $100 \cdot 0$ & 145 & $100 \cdot 0$ & & 608 & $100 \cdot 0$ \\
\hline \multicolumn{8}{|c|}{ Exclusive breast-feeding up to 6 months } \\
\hline No $(n 249)$ & 188 & 53.4 & 61 & 57.5 & 0.453 & 249 & 54.4 \\
\hline Yes (n 209) & 164 & 46.6 & 45 & 42.5 & & 209 & $45 \cdot 6$ \\
\hline Total ( $n$ 458) & 352 & $100 \cdot 0$ & 106 & $100 \cdot 0$ & & 458 & $100 \cdot 0$ \\
\hline
\end{tabular}

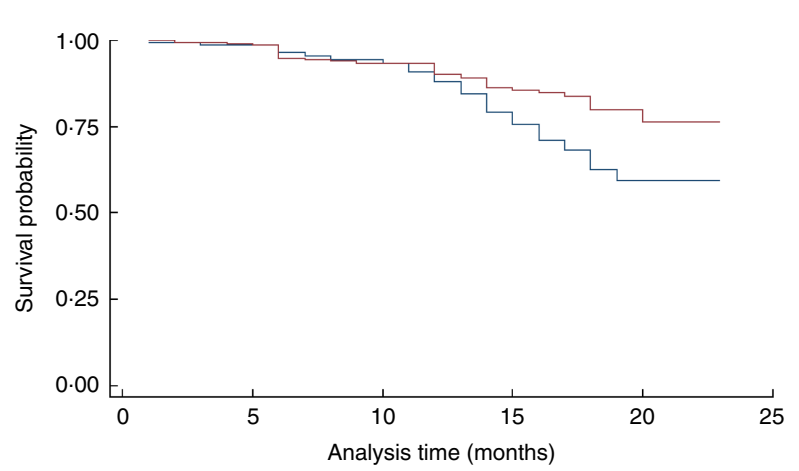

Fig. 1 (colour online) Kaplan-Meier survival estimates of breast-feeding duration in months in 18-49-year-old women with a child under 2 years of age according to receipt of a community-level breast-feeding promotion intervention on breast-feeding practices (- programme township; non-programme township), Myanmar, AugustSeptember 2016

misconceptions and family pressure to give foods other than breast milk have been reported in Myanmar ${ }^{(16,21)}$ and other parts of the world ${ }^{(26-28)}$. This suggests that community-based breast-feeding programmes should reach family members and spouses to help support mothers in exclusively breast-feeding. It should also be noted that the programme may have not had a significant effect on early initiation of breast-feeding because, overall, there are high levels of early initiation (over $90 \%$ in the total sample). Therefore, because the majority of women were already initiating breast-feeding early, the community programme had less influence on changing this behaviour. This was also found in another study of Burmese along the Thai-Myanmar border in which high levels of initiation of breast-feeding was found due to a strong culture of breast-feeding practices ${ }^{(29)}$.

The current study is important for a number of reasons. Myanmar has high rates of neonatal mortality ${ }^{(30)}$ and women have limited access to primary health care. Additionally, the majority of the country's population lives in regions and rural areas where community-based health promotion programmes could be an effective way to improve maternal and newborn health ${ }^{(31)}$. Globally, exclusive breast-feeding and longer duration of breast-feeding are important strategies to reduce newborn and child deaths. For example, past community-based breast-feeding promotion programmes in Nepal have found that neonatal mortality may be substantially reduced if breast-feeding is initiated within the first $24 \mathrm{~h}$ of life ${ }^{(6)}$.

Moreover, the current study found poor breast-feeding practices among women living in hard-to-reach townships. While over $90 \%$ reported breast-feeding within the first $24 \mathrm{~h}$, there were low levels of exclusive breast-feeding with only $45.6 \%$ exclusively breast-feeding. These levels are similar those from the first Demographic and Health Survey in Myanmar, which found that approximately $51 \%$ of women reported exclusive breast-feeding ${ }^{(15)}$. Our results may be slightly lower than the national average because these townships are classified as hard-to-reach areas according to geographic location, transportation difficulties and poor maternal and child health indictors. Women in these areas may be poorer and less knowledgeable about exclusive breast-feeding practices compared with those living in other parts of the country. In our study, women in higher wealth quintile groups were more likely to exclusively breast-feed compared with women in poorer groups. Other studies in low-resource settings have similarly found that poorer women are less likely to exclusively breast-feed than richer women ${ }^{(26)}$. This could be because poorer women may have less flexibility in their work to continue breast-feeding or less support with breast-feeding from health workers or family members.

However, it is interesting to note from the current findings that women in rural areas were more likely to exclusively breast-feed compared with urban populations. This is particularly important given that Myanmar is currently experiencing high levels of internal migration, particularly women moving from rural to urban areas ${ }^{(32)}$. It is therefore important to understand how best to target education activities for women who live in both urban and rural areas for breastfeeding practices. Other studies in Asia have also found higher levels of exclusive breast-feeding in rural compared with urban areas ${ }^{(27,33)}$. This could be related to labour force participation, as other studies have found that women who occupied management/supervisory jobs were more likely 
Table 3 Multivariate logistic regression analysis of breast-feeding rates among 18-49-year-old women with a child under 2 years of age, Myanmar, August-September 2016

\begin{tabular}{|c|c|c|c|c|}
\hline & \multicolumn{2}{|c|}{$\begin{array}{l}\text { Breast-feeding } \\
\text { within } 24 \mathrm{~h}\end{array}$} & \multicolumn{2}{|c|}{$\begin{array}{l}\text { Exclusive } \\
\text { breast-feeding } \\
\text { up to } 6 \text { months }\end{array}$} \\
\hline & AOR & $95 \% \mathrm{Cl}$ & AOR & $95 \% \mathrm{Cl}$ \\
\hline \multicolumn{5}{|l|}{ Age (ref.: 18-24 years) } \\
\hline $25-30$ years & 1.09 & $0.46,2.58$ & 0.92 & $0.49,1.74$ \\
\hline $31-39$ years & $1 \cdot 18$ & $0.39,3.60$ & 0.63 & $0.29,1.37$ \\
\hline $40-49$ years & 1.70 & $0.30,9.58$ & 1.83 & $0.59,5.69$ \\
\hline \multicolumn{5}{|l|}{ Age at marriage (ref.: $<18$ years) } \\
\hline $18-24$ years & $1.96^{*}$ & $0.91,4.22$ & 1.26 & $0.72,2.21$ \\
\hline $25-30$ years & 1.11 & $0.36,3.40$ & 0.95 & $0.41,2 \cdot 22$ \\
\hline $31-39$ years & 0.73 & $0.12,4.36$ & 0.54 & $0.10,2.78$ \\
\hline $40-49$ years & - & - & - & - \\
\hline \multicolumn{5}{|l|}{ Education status (ref.: illiterate or no formal education) } \\
\hline Primary education & 1.77 & $0.69,4.52$ & 1.66 & $0.85,3.23$ \\
\hline Secondary education & 1.95 & $0.78,4.91$ & 1.35 & $0.69,2.61$ \\
\hline University education & 1.63 & $0.34,7 \cdot 70$ & 1.62 & $0.52,5.11$ \\
\hline \multicolumn{5}{|c|}{ Occupation status (ref.: management and supervisory staff, self-employed, businesswoman) } \\
\hline Shop owner, family business & 0.32 & $0.06,1.71$ & 0.50 & $0.14,1.83$ \\
\hline Unskilled worker & $1 \cdot 11$ & $0.20,6.15$ & 0.72 & $0.22,2.40$ \\
\hline Unemployed/housewife & 0.96 & $0.20,4.63$ & 0.65 & $0.21,2.06$ \\
\hline \multicolumn{5}{|l|}{ Parity (ref.: $0-1)$} \\
\hline $2-3$ & 1.51 & $0.69,3.30$ & 1.02 & $0.57,1.83$ \\
\hline $4-5$ & 1.47 & $0.48,4.54$ & 1.02 & $0.48,2 \cdot 19$ \\
\hline$\geq 6$ & 1.78 & $0.29,11.02$ & 0.88 & $0.30,2.62$ \\
\hline Migrant (ref.: non-migrant) & 0.66 & $0.35,1.25$ & 0.80 & $0.50,1.28$ \\
\hline Urban (ref.: rural) & 1.01 & $0.43,2.40$ & $0.53^{\star *}$ & $0.29,0.99$ \\
\hline \multicolumn{5}{|l|}{ Wealth quintile (ref.: lowest quintile) } \\
\hline Lower quintile & 0.78 & $0.22,2.84$ & $2 \cdot 01^{*}$ & $0.97,4.14$ \\
\hline Middle quintile & 0.67 & $0 \cdot 20,2 \cdot 27$ & 1.75 & $0.86,3.55$ \\
\hline Higher quintile & 0.40 & $0.12,1.35$ & $2 \cdot 77^{\star \star \star}$ & $1.32,5 \cdot 84$ \\
\hline Highest quintile & 0.77 & $0.20,2.98$ & $2 \cdot 71^{* *}$ & $1 \cdot 18,6 \cdot 24$ \\
\hline \multicolumn{5}{|l|}{ Antenatal care (ref.: no antenatal care) } \\
\hline $1-4$ visits & 0.59 & $0.12,2.96$ & 0.75 & $0.29,1.92$ \\
\hline$>4$ visits & 0.71 & $0.15,3.35$ & 0.73 & $0.30,1.77$ \\
\hline Delivery place (ref.: home delivery) & 0.80 & $0.43,1.49$ & 1.19 & $0.77,1.83$ \\
\hline State & $0.80^{* *}$ & $0.65,0.97$ & 1.01 & $0.88,1.17$ \\
\hline Constant & $22.57^{* *}$ & $1.39,365.43$ & 0.44 & $0.07,2.83$ \\
\hline Observations $(n)$ & 598 & & 446 & \\
\hline
\end{tabular}

AOR, adjusted odds ratio; ref., reference category.

${ }^{\star} P<0.1,{ }^{\star \star} P<0.05,{ }^{\star \star *} P<0.01$.

to stop breast-feeding earlier compared with women in other occupations. This finding is corroborated by some qualitative studies in Myanmar, which found that labour demands such as having to return to work and having limited time to breast-feed their children at home were significant barriers to exclusive breast-feeding ${ }^{(16,17)}$. A survey in Myanmar also found similar results for complementary feeling practices ${ }^{(34)}$. Taken together, this suggests that educating women about the benefits of exclusive breast-feeding and duration of breast-feeding is not enough. Future programmes need to also take account of how to support women and their families to meet economic and social demands.

There are a number of limitations to the present study. First, these results are based on cross-sectional data, which limits our ability to suggest causal results; however, we are able to compare townships with the intervention $v$. those that did not receive the intervention. Second, the intervention and control townships were not randomized at the start of the study. Therefore, differences between the two townships may explain the associations found in the study. In an effort to account for this, we controlled for demographic characteristics in our multivariable regressions; however, there may be additional unmeasured factors. Another potential limitation of the study is that the control townships may already have maternal and neonatal health activities being implemented by other agencies. These activities included providing support to government basic health staff who perform routine maternal and child health activities in general; for example, seeking pregnant women for antenatal care, attending the delivery and performing postnatal care and vaccinations. The activities did not focus on specific breastfeeding practice only. Therefore, this may have decreased the effect of the intervention. However, the current study found significant differences between intervention and 
Table 4 Cox proportional hazards model for breast-feeding cessation among 18-49-year-old women with a child under 2 years of age, Myanmar, August-September 2016

\begin{tabular}{|c|c|c|}
\hline & $\mathrm{HR}$ & $95 \% \mathrm{Cl}$ \\
\hline \multicolumn{3}{|l|}{ Age (ref.: 18-24 years) } \\
\hline $25-30$ years & 0.95 & $0.44,2.05$ \\
\hline $31-39$ years & 0.64 & $0.24,1.75$ \\
\hline 40-49 years & 0.85 & $0.21,3.51$ \\
\hline \multicolumn{3}{|l|}{ Age at marriage (ref.: <18 years) } \\
\hline $18-24$ years & $1 \cdot 12$ & $0.56,2 \cdot 23$ \\
\hline $25-30$ years & 0.50 & $0.15,1.69$ \\
\hline $31-39$ years & 1.71 & $0.27,10.88$ \\
\hline \multicolumn{3}{|l|}{ Education status (ref.: illiterate or no formal education) } \\
\hline Primary education & 0.96 & $0.44,2 \cdot 11$ \\
\hline Secondary education & 0.98 & $0.45,2.13$ \\
\hline University education & 0.42 & $0.08,2 \cdot 14$ \\
\hline \multicolumn{3}{|c|}{ Occupation category (ref.: management and supervisory staff, self-employed, businesswoman) } \\
\hline Shop owner, family business & $0 \cdot 13^{\star \star}$ & $0.02,0.89$ \\
\hline Unskilled worker & 0.40 & $0.09,1.73$ \\
\hline Unemployed/housewife & 0.34 & $0.08,1.37$ \\
\hline \multicolumn{3}{|l|}{ Parity (ref.: $0-1$ ) } \\
\hline $2-3$ & 0.99 & $0.48,2.06$ \\
\hline $4-5$ & 0.91 & $0.33,2.50$ \\
\hline$\geq 6$ & 0.37 & $0.07,2.16$ \\
\hline Migrant (ref.: non-migrant) & 0.71 & $0.38,1.33$ \\
\hline Urban (ref.: rural) & 1.28 & $0.64,2.53$ \\
\hline \multicolumn{3}{|l|}{ Wealth quintile (ref.: lowest quintile) } \\
\hline Lower quintile & $3.49^{*}$ & $0.98,12.42$ \\
\hline Middle quintile & $2 \cdot 81$ & $0.79,10.00$ \\
\hline Higher quintile & $3.50^{\star}$ & $0.96,12.69$ \\
\hline Highest quintile & $3.47^{\star}$ & $0.92,13.07$ \\
\hline \multicolumn{3}{|l|}{ Antenatal care (ref.: no antenatal care) } \\
\hline $1-4$ visits & 1.88 & $0.41,8.56$ \\
\hline$>4$ visits & 1.37 & $0 \cdot 31,6 \cdot 10$ \\
\hline Delivery place (ref.: home delivery) & 1.02 & $0.60,1.74$ \\
\hline State & $1 \cdot 12$ & $0.92,1.35$ \\
\hline Observations $(n)$ & 580 & \\
\hline
\end{tabular}

$\mathrm{HR}$, hazard ratio; ref., reference category.

${ }^{\star} P<0.1,{ }^{\star \star} P<0.05,{ }^{\star \star \star} P<0.01$.

control townships, despite the potential muted effect. Fourth, the intervention duration was not consistent across townships as some received it earlier than others. Because of the limited sample size, we were not able to assess the dose response of the intervention. The last limitation to note in the current study is the possibility of biases in reporting of breast-feeding practices. Women were asked to recall events that had happened in the past, including whether they breast-fed immediately after birth, exclusively breast-fed in the first 6 months of their child's life and how long they breast-fed. Therefore, there may be recall bias in the accuracy of responses. Because the programme was specifically rolled out at a community level, social desirability bias ${ }^{(35)}$ may also influence results, given that women may be aware of the programme and the importance of exclusive breast-feeding and may thus over-report breast-feeding practices. Moreover, some women may be confused about what exclusive breastfeeding means. Past qualitative studies suggest that women do not always understand the meaning of exclusive breast-feeding, believing that water and other liquids can be given to newborns and still be considered exclusive $^{(16)}$. The present study did ask a question about whether mothers gave water to their infant and we specifically constructed our outcome measure of exclusive breast-feeding as those who did not report giving water before 6 months. Lastly, while we have responses of women, other studies have found that other family members may be involved in feeding newborns, including mothers-in-law and husbands ${ }^{(16)}$. Therefore, future surveys may also want to include other family members' reports of feeding.

Community-based interventions to improve breastfeeding practices are urgently needed in Myanmar. Despite these limitations, there are a number of recommendations that can be made based on the present study's findings. Innovative programmes and strategies are needed to improve breast-feeding practices among hard-toreach populations. Future programmes should customize strategies that will enable specific target groups to practise recommended breast-feeding practices, including urban women who may need to work. Programmes may include other family members to help support mothers in breastfeeding, including husbands and mothers-in-law. In addition, emphasis is needed in delivering messages about exclusivity of breast-feeding up to 6 months of children's 
age. Community-based activities have the potential to positively improve breast-feeding duration as revealed herein; therefore, future programmes should continue to empower communities given the substantial benefits of a longer duration of breast-feeding.

\section{Acknowledgements}

Acknowledgements: The authors would like to thank the donor, the Three Millennium Development Goal Fund (3MDG), for providing financial support for the study. In addition, they express thanks to Dr Swai Mon Oo (Senior Research Officer, Research Unit of Strategic Information Department) who assisted in data cleaning and data management; Neo Prospect Research Agency for data collection; and staff from the Reproductive Health team of the Program Management Division, PSI/M, for other support to the study. The authors would also like to thank each woman who participated in the survey. Financial support: This work was supported by 3MDG. 3MDG had no role in the design, analysis or writing of this article. Conflict of interest: The authors have no conflicts of interest to declare. Authorship: M.M.T. led the analysis and writing of the paper; T.A. conceived of the study and contributed to the interpretation of the paper; N.D.-S. contributed to the analysis of the paper, interpretation of the study results and writing of the paper; M.S. designed the analysis of the paper and contributed to the interpretation of the study results and writing of the paper. Ethics of buman subject participation: This study was conducted according to the guidelines laid down in the Declaration of Helsinki and all procedures involving human subjects were approved by the PSI/M Research Ethics Board. Verbal informed consent was obtained from all subjects. Verbal consent was witnessed and formally recorded.

\section{Supplementary material}

To view supplementary material for this article, please visit https://doi.org/10.1017/S1368980018001799

\section{References}

1. Smith ER, Locks LM, Manji KP et al. (2017) Delayed breastfeeding initiation is associated with infant morbidity. $J$ Pediatr 191, 57-62.e2.

2. Smith ER, Hurt L, Chowdhury R et al. (2017) Delayed breastfeeding initiation and infant survival: a systematic review and meta-analysis. PLoS One 12, e0180722.

3. Debes AK, Kohli A, Walker N et al. (2013) Time to initiation of breastfeeding and neonatal mortality and morbidity: a systematic review. BMC Public Health 13, Suppl. 3, S19.

4. Victora CG, Bahl R, AJD Barros et al. (2016) Breastfeeding in the 21st century: epidemiology, mechanisms, and lifelong effect. Lancet 387, 475-490.
5. Garcia CR, Mullany LC, Rahmathullah L et al. (2011) Breastfeeding initiation time and neonatal mortality risk among newborns in South India. J Perinatol 31, 397-403.

6. Mullany LC, Katz J, Li YM et al. (2008) Breast-feeding patterns, time to initiation, and mortality risk among newborns in southern Nepal. J Nutr 138, 599-603.

7. Hajeebhoy N, Nguyen PH, Mannava P et al. (2014) Suboptimal breastfeeding practices are associated with infant illness in Vietnam. Int Breastfeed J 9, 12.

8. Arifeen S, Black RE, Antelman G et al. (2001) Exclusive breastfeeding reduces acute respiratory infection and diarrhea deaths among infants in Dhaka slums. Pediatrics 108, E67.

9. Kramer MS, Aboud F, Mironova E et al. (2008) Breastfeeding and child cognitive development: new evidence from a large randomized trial. Arch Gen Psychiatry 65, 578-584.

10. Mortensen EL, Michaelsen KF, Sanders SA et al. (2002) The association between duration of breastfeeding and adult intelligence. JAMA 287, 2365-2371.

11. Richards M, Hardy R \& Wadsworth MEJ (2002) Long-term effects of breast-feeding in a national birth cohort: educational attainment and midlife cognitive function. Public Health Nutr 5, 631-635.

12. Victora CG, Horta BL, Loret de Mola C et al. (2015) Association between breastfeeding and intelligence, educational attainment, and income at 30 years of age: a prospective birth cohort study from Brazil. Lancet Glob Health 3, e199-e205.

13. Binns C, Lee M \& Low WY (2016) The long-term public health benefits of breastfeeding. Asia Pac J Public Health 28, 7-14.

14. UNICEF (2015) Breastfeeding. http://www.unicef.org/ nutrition/index_24824.html (accessed October 2016).

15. Ministry of Health and Sports \& ICF International (2016) Demographic and Health Survey 2015-16: Key Indicators Report. Nay Pyi Taw, Myanmar and Rockville, MD: MOHS and ICF International.

16. Thet MM, Khaing EE, Diamond-Smith N et al. (2016) Barriers to exclusive breastfeeding in the Ayeyarwaddy region in Myanmar: qualitative findings from mothers, grandmothers, and husbands. Appetite 96, 62-69.

17. Hmone MP, Dibley MJ, Li M et al. (2016) A formative study to inform mHealth based randomized controlled trial intervention to promote exclusive breastfeeding practices in Myanmar: incorporating qualitative study findings. $B M C$ Med Inform Decis Mak 16, 60.

18. Hmone MP, Li M, Agho K et al. (2017) Factors associated with intention to exclusive breastfeed in central women's hospital, Yangon, Myanmar. Int Breastfeed J 12, 29.

19. Thin Thin D (2003) Beliefs, Attitudes, and Practices of Mother Regarding Exclusive Breast Feeding in Myanmar. Melbourne: School of Nursing and Midwifery, La Trobe University.

20. Saw YM, Win KL, Shiao LW-S et al. (2013) Taking stock of Myanmar's progress toward the health-related Millennium Development Goals: current roadblocks, paths ahead. Int J Equity Health 12, 78.

21. Linn S (2011) UNICEF Myanmar I Health \& Nutrition I Exclusive Breastfeeding Celebrated by Rural Myanmar Family. https://www.unicef.org/myanmar/health_nutrition_16806. html (accessed June 2018).

22. Haider R, Ashworth A, Kabir I et al. (2000) Effect of community-based peer counsellors on exclusive breastfeeding practices in Dhaka, Bangladesh: a randomised controlled trial. Lancet 356, 1643-1647.

23. Crookston BT, Dearden KA, Chan K et al. (2007) Buddhist nuns on the move: an innovative approach to improving breastfeeding practices in Cambodia. Matern Child Nutr $\mathbf{3}$, $10-24$. 
24. Darmstadt GL, Choi Y, Arifeen SE et al. (2010) Evaluation of a cluster-randomized controlled trial of a package of community-based maternal and newborn interventions in Mirzapur, Bangladesh. PLoS One 5, e9696.

25. Filmer D \& Pritchett LH (2001) Estimating wealth effects without expenditure data - or tears: an application to educational enrollments in states of India. Demography $\mathbf{3 8}$, 115-132.

26. Agho KE, Dibley MJ, Odiase JI et al. (2011) Determinants of exclusive breastfeeding in Nigeria. BMC Pregnancy Childbirth 11, 2.

27. Tan KL (2011) Factors associated with exclusive breastfeeding among infants under six months of age in peninsular Malaysia. Int Breastfeed J 6, 2.

28. Arts M, Geelhoed D, De Schacht C et al. (2011) Knowledge, beliefs, and practices regarding exclusive breastfeeding of infants younger than 6 months in Mozambique: a qualitative study. J Hum Lact 27, 25-32.

29. White AL, Carrara VI, Paw MK et al. (2012) High initiation and long duration of breastfeeding despite absence of early skin-to-skin contact in Karen refugees on the Thai-Myanmar border: a mixed methods study. Int Breastfeed J 7, 19.
30. World Health Organization (2015) Neonatal and Child Health Country Profile. Geneva: WHO.

31. Adam MB, Dillmann M, Chen $M$ et al. (2014) Improving maternal and newborn health: effectiveness of a community health worker program in rural Kenya. PLoS One 9, e104027.

32. Sudhinaraset M, Diamond-Smith N, Thet MM et al. (2016) Influence of internal migration on reproductive health in Myanmar: results from a recent cross-sectional survey. BMC Public Health 16, 246.

33. Gao H, Wang Q, Hormann E et al. (2016) Breastfeeding practices on postnatal wards in urban and rural areas of the Deyang region, Sichuan province of China. Int Breastfeed J 11, 11.

34. Thet MM, Richards L-M, Sudhinaraset M et al. (2016) Assessing rates of inadequate feeding practices among children 12-24 months: results from a cross-sectional survey in Myanmar. Matern Child Health J 20, 1688-1695.

35. Grimm P (2010) Social desirability bias. In Wiley International Encyclopedia of Marketing [J Sheth and N Malhotra, editors]. https://doi.org/10.1002/9781444316568.wiem02057 (accessed August 2018). 